\title{
Balanced Dual Composite Right/Left-Handed Microstrip Line with Modified Complementary Split Ring Resonators
}

\author{
Angel Belenguer, Member, IEEE, Alejandro L. Borja, and Vicente E. Boria, Senior Member, IEEE
}

\begin{abstract}
This paper presents a dual composite right/lefthanded microstrip line loaded with modified complementary split ring resonators. In this particular case, the well known resonant particle employed has been capacitively loaded in order to obtain a balanced frequency response. The inclusion of this capacitive element has two main effects. On the one hand, the rightand left-handed bands are interchanged. On the other hand, the possibility to control the position of the right-handed band, while maintaining the left-handed one unaltered. Consequently, it is relatively simple to design balanced transmission lines with improved bandwidth and reconfigurable properties. In addition, the equivalent circuit that describes the electromagnetic behavior of the structure has been obtained. Finally, a prototype has been fabricated and measured to confirm experimentally the validity of the proposed design.
\end{abstract}

Index Terms-Composite right/left-handed (CRLH) transmission lines, complementary split ring resonators (CSRR), dual composite right/left-handed (D-CRLH) transmission lines, equivalent circuit model, microstrip lines.

\section{INTRODUCTION}

$\mathbf{S}^{1}$ INCE the proposal of the first metamaterial based transmission lines [1], [2], different new approaches have been analyzed and presented to the scientific community. Generally, these transmission lines with novel properties have been obtained by using a host transmission line loaded with resonators [3]-[22]. The synthesis of these effective media requires electrically small unit cells using sub-wavelength resonators. The resonators can be coupled in different ways, i.e. inductive or capacitive coupling, giving rise to many different kinds of transmission lines. In this regard, split ring resonators (SRRs) coupled to a coplanar waveguide (CPW) [3]-[9] have been employed in order to obtain lines with symmetric, highly selective responses with an excellent tradeoff between insertion losses and selectivity, and good quality factors or reconfigurable BW. In addition, complementary split ring resonators (CSRRs) based microstrip lines [10]-[14] have been presented with the prospect to achieve transmission lines and filters with electrically small size dimensions, balanced

This work was supported by the Ministerio de Ciencia e Innovación, Spanish Goverment, under Research Projects TEC2010-21520-C04-03 and -01 , and by the Autonomous Government of Castilla-La Mancha under Research Projects PPII10-0047-0220 and PPII10-0027-1277.

A. Belenguer and A. L. Borja are with Departamento de Ingeniería Eléctrica, Electrónica, Automática y Comunicaciones, Universidad de CastillaLa Mancha, Escuela Politécnica de Cuenca, Campus Universitario, 16071 Cuenca, Spain (e-mail: angel.belenguer@uclm.es; alejandro.lucas@uclm.es).

V. E. Boria is with Departamento de Comunicaciones, Universidad Politécnica de Valencia, 46022 Valencia, Spain (e-mail: vboria@dcom.upv.es). composite right/left handed (CRLH) transmission lines with improved bandwidth responses or multi-band functionality. Based on these two previous configurations, novel resonanttype elements that load different transmission lines have been successfully proposed. Recently, inductively connected split ring resonators (IC-SRRs) [15], open split ring resonators (OSRRs) [16], open complementary split ring resonators (OCSRRs) [17] and different loaded resonators [18]-[22] have been presented. The aforementioned topologies have allowed to assemble new transmission lines with novel properties.

In this paper, we present a balanced dual CRLH microstrip lines based on modified CSRRs with improved frequency response in terms of bandwidth and reconfigurability. Moreover, its accurate equivalent circuit representation is described, which in this case has been obtained directly from the physical arrangement of the structure, conversely to previous studies where it was obtained applying the Babinet's principle. As a consequence, the proposed equivalent circuit permits to model any geometrical change of the ring. The paper is organized as follows. In section II, the new proposed modified version of the CSRR based transmission line and its equivalent circuit are presented. In Section III, results obtained based on the scattering parameters and dispersion diagram of the equivalent circuit model, full-wave electromagnetic analysis, and measured responses are shown. Finally, the main conclusions of this work are outlined in Section IV.

\section{Modified BASIC CELL}

In this section, a modification of former CSRR loaded microstrip line cells [2], [11], [12] is proposed. The layout and its related geometrical parameters are described in Fig. 1 and Table I.

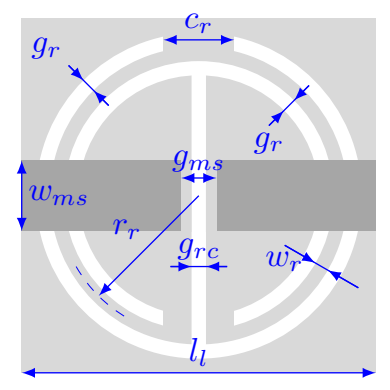

Fig. 1. Layout of the microstrip cell (top view for a transparent substrate) loaded with a modified CSRR. Dark gray is metal on top layer; light gray is metal on bottom layer 
As it can be observed, the CSRR particle has been modified. More specifically, the CSRR central conductor has been split into two parts. Each half of this central conductor, are now electrically coupled through the inserted gap, synthesizing thus a new capacitance. This capacitance can be controlled by simply modifying the dimension denoted as $g_{r c}$. Finally, the substrate employed to design the basic cell has been a Rogers $4003 \mathrm{C}^{\mathrm{TM}}$ dielectric substrate with relative permittivity $\epsilon=3.55$ and thickness $1.524 \mathrm{~mm}$.

In addition, an axial cut of the capacitively split CSRR loaded microstrip cell, a top view of the cell, and the equivalent circuit that can be inferred from these representations can be found in Fig. 2. The values of the lumped elements are also presented in Table I.

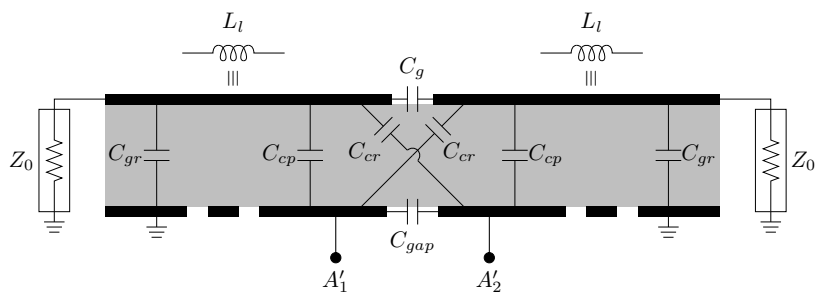

(a) Axial view

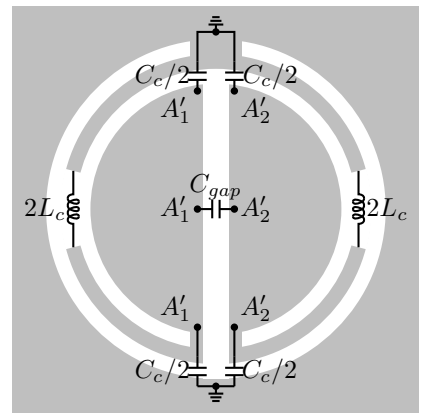

(b) Top view

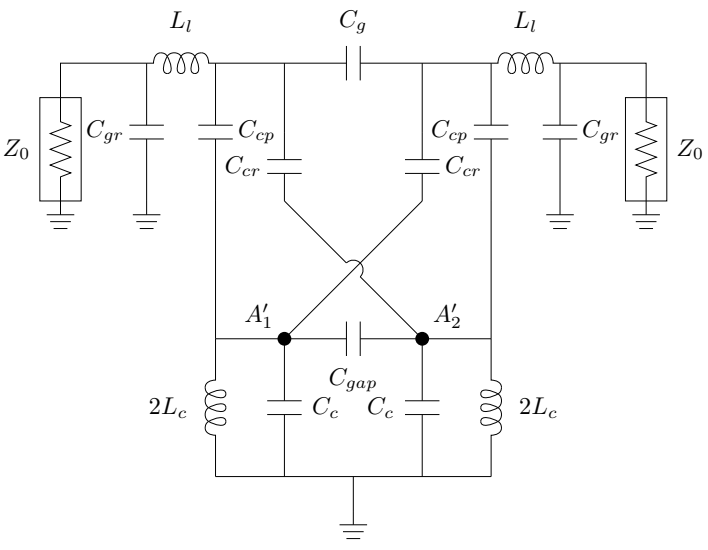

(c) Equivalent circuit

Fig. 2. a) Axial cut of the CSRR loaded microstrip cell. Black is metal and gray is substrate. (b) Top view of the split CSRR loaded microstrip cell. Gray is metal. (c) Proposed equivalent circuit for split CSRR loaded microstrip line.

The proposed equivalent circuit model has two major modifications with repect to former descriptions presented in [2], [11] and [12]. First, the lumped elements $L_{c}$ and $C_{c}$ that account for the CSRR are divided into two LC resonant tanks. Second, two additional parasitic capacitances $C_{c r}$ that model
TABLE I

PHYSICAL DIMMENSIONS AND LUMPED EQUIVALENT CIRCUIT VALUES OF THE MICROSTRIP CELL LOADED WITH A SPLIT CSRR.

\begin{tabular}{llll} 
& Physical Dimensions & & Lumped element values \\
\hline$w_{m s}$ & $3.37 \mathrm{~mm}$ & $L_{l}$ & $2.05 \mathrm{nH}$ \\
$g_{m s}$ & $0.5 \mathrm{~mm}$ & $C_{g r}$ & $0.33 \mathrm{pF}$ \\
$r_{r}$ & $3.64 \mathrm{~mm}$ & $C_{c p}$ & $0.27 \mathrm{pF}$ \\
$c_{r}$ & $2 \mathrm{~mm}$ & $C_{g}$ & $0.081 \mathrm{pF}$ \\
$w_{r}$ & $0.4 \mathrm{~mm}$ & $C_{c r}$ & $0.043 \mathrm{pF}$ \\
$g_{r}$ & $0.4 \mathrm{~mm}$ & $C_{g a p}$ & $0.083 \mathrm{pF}$ \\
$g_{r c}$ & $0.85 \mathrm{~mm}$ & $L_{c}$ & $2.19 \mathrm{nH}$ \\
$l_{l}$ & $11 \mathrm{~mm}$ & $C_{c}$ & $0.305 \mathrm{pF}$ \\
\hline
\end{tabular}

the capacitive coupling of one side of the CSRR with the microstrip at the opposite side of the cell must be incorporated to the equivalent circuit. The use of these parasitic capacitances permit to control the slopes of the response out of the pass band. As it can be observed, the use of the Babinet principle cannot be employed when the complementary of the SRR is altered. It is necessary to extract the lumped elements analyzing the shape of the resonator, and interpreting the electromagnetic interactions among the different elements of the cell. Finally, the elements of the equivalent circuit have been calculated following the same procedure described in [2]. Moreover, the capacitor $C_{g a p}$ has been estimated with the capacitance of a microstrip gap [23] for a line of the same width as the diameter of the internal conductor of the CSRR. Once the initial parameters have been calculated, excluding the capacitance $C_{c r}$ that has been fixed to $0 p F$, all components are slightly tuned by optimization in order to match both simulated results, i.e. the full-wave simulation and the circuital response. Fig. 3 shows the transmission and reflection coefficients of the modified CSRR based microstrip line.

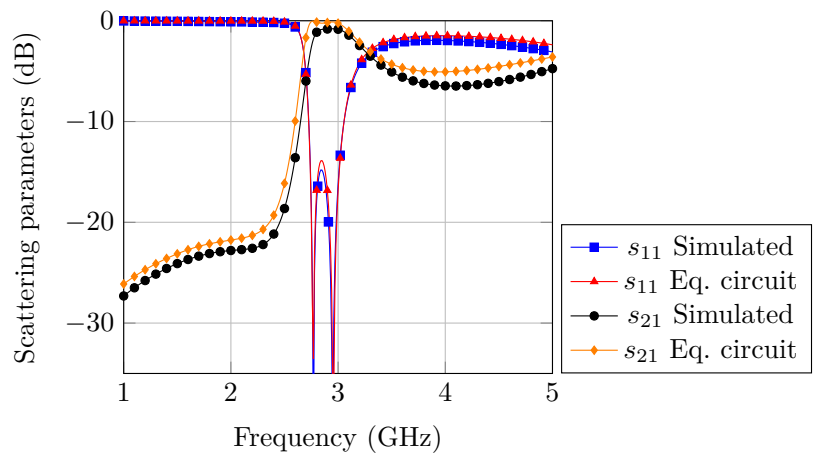

Fig. 3. Equivalent circuit vs. simulated $\left(\mathrm{HFSS}^{\mathrm{TM}}\right.$ ) scattering parameters for the microstrip cell loaded with a split CSRR.

The agreement between the electrical and full-wave simulations is excellent. Indeed, the equivalent circuit response is able to follow any variation of the full-wave response in terms of slope changes and magnitude depth, thus validating the proposed equivalent circuit. It can be observed that the insertion of the gap by partially removing the metal inside the resonator, permits to obtain a new transmission band below $3 \mathrm{GHz}$, enhancing the bandwidth and keeping a low insertion loss level. 


\section{EXPERIMENTAL Results}

Finally, the proposed cell has been fabricated (see Fig. 4). This prototype has been fabricated using a mechanical milling machine (LPKF ${ }^{\mathrm{TM}}$ Protomat S103), which inherently introduces a systematic over-milling. It has been noticed by analyzing different fabricated prototypes that an over-milling depth of around $60 \mu \mathrm{m}$ is obtained. This fabrication mismatch is the main responsible of undesired frequency shifts. Fortunately, it is possible to overcome this problem by taking into account the over-milling during the full-wave simulation, which has been the case. The final dimensions obtained are given in the caption of Fig. 4.

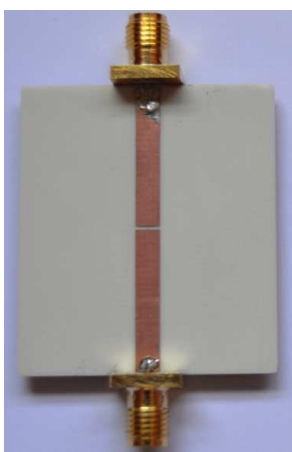

(a) Top

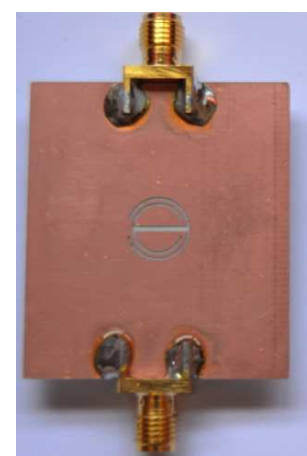

(b) Bottom
Fig. 4. Fabricated modified CSRR loaded microstrip cell. Dimensions after considering overmilling are $w_{m s}=3.37, g_{m s}=0.5, r_{r}=3.68, c_{r}=2$, $w_{r}=0.4, g_{r}=0.4, g_{r c}=0.8$ and $l_{l}=11$. Dimensions are in $\mathrm{mm}$.

The measured S-parameters are depicted in Fig. 5 and compared to the HFSS simulation. Measurements have been obtained by means of the Anritsu ${ }^{\text {TM }}$ vector network analyzer calibrated with a Through-Open-Short Match kit, in the frequency band from 1 to $5 \mathrm{GHz}$. Good agreement between the experimental results and the electromagnetic simulation has been obtained, which validates the over-milling calculation employed during simulations. The discrepancies observed can be attributed to the connectors and soldering imperfections.

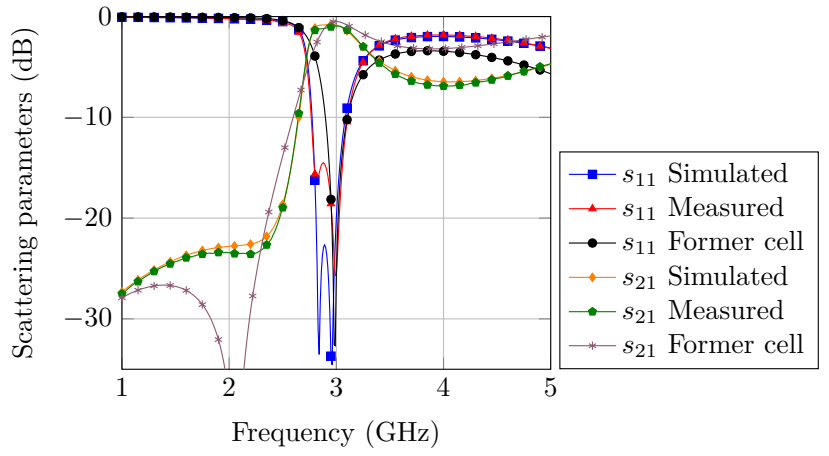

Fig. 5. Measured vs. simulated (considering over-milling with $\mathrm{HFSS}^{\mathrm{TM}}$ ) scattering parameters for the microstrip cell loaded with a split CSRR. The results of the traditional cell have been included in order to highlight the benefits of the new proposed configuration.

Clearly, the modification of the CSRR permits to introduce a new transmission band, whose position can be controlled by the width $g_{r c}$ (represented by the capacitance $C_{g a p}$ in the equivalent circuit model). The wider the gap is, the lower the capacitance results. Consequently, in this case the additional band is shifted to upper frequencies. Likewise, this band can be moved to lower frequencies by simple diminishing the gap width $g_{r c}$. Obviously, the basic cell can be easily balanced by simply designing this parameter. According to the results, it is clear that wider bandwidths can be obtained for the same size of the unit cell. The measured fractional bandwidth (FBW) where $S_{21}>\max \left(S_{21}\right)-0.3 \mathrm{~dB}$ is $8.7 \%$ for the balanced dual CRLH cell, whilst it is $2.6 \%$ for the loaded microstrip line using conventional CSRRs (the results of a simulated unit cell are shown in Fig. 5). Besides, it is quite simple to control the frequency response and obtain reconfigurable performances of this novel unit cell by altering the dimensions of the structure.

Finally the composite right/left-handed nature of the new cell has been studied. To this end, we have retrieved (see Fig. $6)$ the permittivity and permeability responses as indicated in [24]. Also, the phase constant of the resulting composite transmission line (see Fig. 7) has been obtained following the standard procedure described in reference [25], where the aforementioned phase constant, $\beta$, is retrieved from this equation:

$$
\beta l_{l}=\cos ^{-1}\left(\frac{1-S_{11} S_{21}+S_{12} S_{21}}{2 S_{21}}\right)
$$

where $l_{l}$ is the unit cell period, and $S_{11}, S_{12}, S_{21}$ and $S_{22}$ are the scattering parameters of the basic cell.

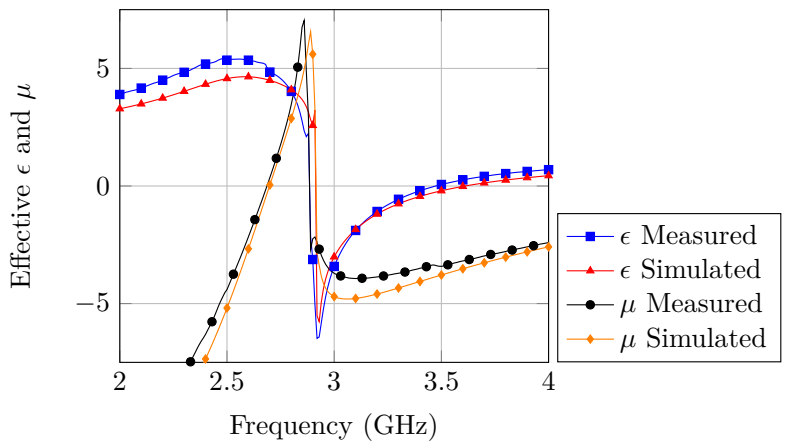

Fig. 6. Measured vs. simulated (considering over-milling with $\mathrm{HFSS}^{\mathrm{TM}}$ ) retrieved effective $\epsilon$ and $\mu$ for the microstrip cell loaded with a split CSRR.

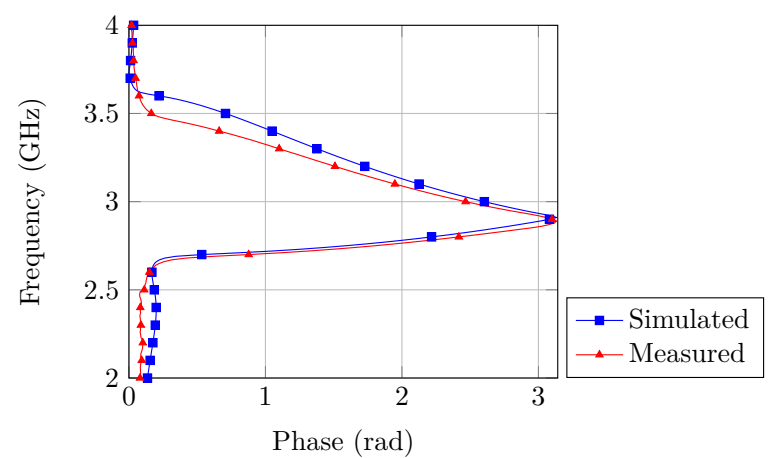

Fig. 7. Measured vs. simulated (considering over-milling with $\mathrm{HFSS}^{\mathrm{TM}}$ ) dispersion diagram for the microstrip cell loaded with a split CSRR. 
As it can be seen, measurements confirm that the proposed loaded transmission lines have two propagation bands with different nature around $3 \mathrm{GHz}$. The first frequency band, below $2.9 \mathrm{GHz}$, is attributed to a right-handed propagation since $\beta$ increases as a function of frequency and $\epsilon$ and $\mu$ are positive. Above $2.9 \mathrm{GHz}$, the phase is inverted (phase diminishes as frequency increases), $\epsilon$ and $\mu$ are both negative, and a lefthanded propagation is achieved with a continuous transition. These results confirm that a balanced dual CLRH line has been successfully designed at $3 \mathrm{GHz}$ by means of the modified CSRRs.

\section{CONCLUSIONS}

In this paper, a modified CSRR based microstrip transmission line has been employed in order to synthesize a balanced dual CRLH cell. The gap etched in the CSRR permits to introduce a new right-handed transmission band that can be easily controlled. Consequently, the artificial transmission line has been balanced by adjusting the dimensions of the resonator, conversely to previous studies where new loading elements are introduced to the design. It is important to note that this new cell cannot be modeled by previous equivalent circuit representations, so that an improved equivalent circuit for modified CSRR based micrsotrip lines has been presented. The equivalent circuit has been obtained directly from the physical topology of the structure. Thus, it permits to represent the behavior of these sort of loaded transmission lines even if the original CSRR particle is altered. In addition, a fabricated prototype has been reported to experimentally characterize the line. It has been found that fractional bandwidths $\left(S_{21}>\right.$ $\left.\max \left(S_{21}\right)-0.3 \mathrm{~dB}\right)$ close to $8.7 \%$ can be achieved by keeping good insertion losses. This bandwidth enhancement is due to the balanced behavior of the devices, which has been established by the interpretation of the dispersion characteristics and retrieved effective $\epsilon$ and $\mu$ of the modified basic cells.

\section{REFERENCES}

[1] F. Martín, J. Bonache, F. Falcone, M. Sorolla, and R. Marqués, "Split ring resonator-based left-handed coplanar waveguide," Applied Physics Letters, vol. 83, no. 22, pp. 4652-4654, 2003.

[2] F. Falcone, T. Lopetegi, J. Baena, R. Marques, F. Martin, and M. Sorolla, "Effective negative- $\epsilon$ stopband microstrip lines based on complementary split ring resonators," IEEE Microwave and Wireless Components Letters, vol. 14, no. 6, pp. 280 - 282, Jun. 2004.

[3] R. Marques, F. Mesa, J. Martel, and F. Medina, "Comparative analysis of edge- and broadside- coupled split ring resonators for metamaterial design - theory and experiments," IEEE Transactions on Antennas and Propagation, vol. 51, no. 10, pp. 2572 - 2581, Oct. 2003.

[4] A. L. Borja, J. Carbonell, V. E. Boria, and D. Lippens, "Symmetrical frequency response in a split ring resonator based transmission line," Appl. Phys. Lett., vol. 93, no. 20, pp. 203 505-1, Nov. 2008.

[5] - "Highly selective left-handed transmission line loaded with split ring resonators and wires," Appl. Phys. Lett., vol. 94, no. 14, 2009.

[6] J. Carbonell, A. L. Borja, V. E. Boria, and D. Lippens, "Duality and superposition in split-ring-resonator-loaded planar transmission lines," IEEE Antennas and Wireless Propagation Letters, vol. 8, pp. 886 -889, 2009.

[7] A. L. Borja, J. Carbonell, V. E. Boria, J. Cascón., and D. Lippens, "A 2\% bandwidth C-band filter using cascaded split ring resonators," IEEE Antennas and Wireless Propagation Letters, vol. 9, pp. 256 -259, 2010.

[8] A. L. Borja, J. Carbonell, V. E. Boria, J. Cascon, and D. Lippens, "Synthesis of compact and highly selective filters via metamaterialinspired coplanar waveguide line technologies," IET Microwaves, Antennas Propagation, vol. 4, no. 8, pp. 1098 -1104, Aug. 2010.
[9] A. L. Borja, A. Belenguer, J. Cascon, H. Esteban, and V. Boria, "Wideband passband transmission line based on metamaterial-inspired CPW balanced cells," IEEE Antennas and Wireless Propagation Letters, vol. 10, no. 12, pp. 1421 -1424, Dec. 2011.

[10] R. Marques, J. D. Baena, J. Martel, F. Medina, F. Falcone, M. Sorolla, and F. Martin, "Novel small resonant electromagnetic particles for metamaterial and filter design," in Proceedings of the International Conference on Electromagnetics in Advanced Applications (ICEAA-03), Torino, Italy, 8-12 Sept. 2003, pp. 439-442.

[11] F. Falcone, T. Lopetegi, M. A. G. Laso, J. D. Baena, J. Bonache, M. Beruete, R. Marques, F. Martin, and M. Sorolla, "Babinet principle applied to the design of metasurfaces and metamaterials," Physical Review Letters, vol. 93, no. 19, p. 197401, 2004.

[12] J. Baena, J. Bonache, F. Martin, R. Sillero, F. Falcone, T. Lopetegi, M. Laso, J. Garcia-Garcia, I. Gil, M. Portillo, and M. Sorolla, "Equivalent-circuit models for split-ring resonators and complementary split-ring resonators coupled to planar transmission lines," IEEE Transactions on Microwave Theory and Techniques, vol. 53, no. 4, pp. 1451 - 1461, Apr. 2005.

[13] J. Bonache, I. Gil, J. Garcia-Garcia, and F. Martin, "Novel microstrip bandpass filters based on complementary split-ring resonators," IEEE Transactions on Microwave Theory and Techniques, vol. 54, no. 1, pp. $265-271$, Jan. 2006

[14] M. Gil, J. Bonache, J. Garcia-Garcia, J. Martel, and F. Martin, "Composite right/left-handed metamaterial transmission lines based on complementary split-rings resonators and their applications to very wideband and compact filter design," IEEE Transactions on Microwave Theory and Techniques, vol. 55, no. 6, pp. 1296 -1304, Jun. 2007.

[15] A. Belenguer, J. Cascon, A. L. Borja, H. Esteban, and V. E. Boria, "Dual composite right/left-handed coplanar waveguide transmission line using inductively connected split-ring resonators," IEEE Trans. on Microwave Theory and Tech., vol. 60, no. 10, pp. 3035-3042, Oct. 2012.

[16] M. Duran-Sindreu, A. Velez, F. Aznar, G. Siso, J. Bonache, and F. Martin, "Applications of open split ring resonators and open complementary split ring resonators to the synthesis of artificial transmission lines and microwave passive components," IEEE Transactions on Microwave Theory and Techniques, vol. 57, no. 12, pp. 3395 -3403, Dec. 2009.

[17] A. Vélez, F. Aznar, J. Bonache, M. C. Velázquez-Ahumada, J. Martel, and F. Martín, "Open complementary split ring resonators (OCSRRs) and their application to wideband CPW band pass filters," IEEE Microwave and Wireless Components Letters, vol. 19, no. 4, pp. 197 -199, Apr. 2009.

[18] I. Gil, J. Garcia-Garcia, J. Bonache, F. Martin, M. Sorolla, and R. Marques, "Varactor-loaded split ring resonators for tunable notch filters at microwave frequencies," Electronics Letters, vol. 40, no. 21, pp. 1347 - 1348, Oct. 2004.

[19] A. L. Borja, J. Carbonell, V. E. Boria, A. Belenguer, and D. Lippens, "A compact coplanar waveguide metamaterial-inspired line and its use in tunable narrow bandpass filters," in European Microwave Conference (EuMC), Sept. 2010, pp. $922-925$.

[20] A. L. Borja, J. Carbonell, J. Martinez, V. Boria, and D. Lippens, "A controllable bandwidth filter using varactor-loaded metamaterialinspired transmission lines," IEEE Antennas and Wireless Propagation Letters, vol. 10, pp. $1575-1578,2011$

[21] C. Caloz, "Dual composite right/left-handed (D-CRLH) transmission line metamaterial," IEEE Microwave and Wireless Components Letters, vol. 16 , no. 11, pp. $585-587$, Nov. 2006.

[22] V. Gonzalez-Posadas, J. Jimenez-Martin, A. Parra-Cerrada, L. GarciaMunoz, and D. Segovia-Vargas, "Dual-composite right-left-handed transmission lines for the design of compact diplexers," IET Microwaves, Antennas Propagation, vol. 4, no. 8, pp. 982 -990, Aug. 2010.

[23] B. C. Wadell, Transmission Line Design Handbook. Artech House, 1991.

[24] D. R. Smith, D. C. Vier, T. Koschny, and C. M. Soukoulis, "Electromagnetic parameter retrieval from inhomogeneous metamaterials," Physical Review E, vol. 71, no. 1, p. 036617, 2005.

[25] C. Caloz and T. Itoh, Electromagnetic Metamaterials: Transmission Line Theory and Microwave Applications. Wiley, 2005. 